\title{
РОЛЬ ГРАЖДАНСКОГО ОБЩЕСТВА В ОБЕСПЕЧЕНИИ ГЛАСНОСТИ МЕСТНОГО САМОУПРАВЛЕНИЯ
}

Аннотация. В статье рассматриваются основные правовые механизмы по обеспечению гласности, прозрачности органов местного самоуправления, которыми наделены институты гражданского общества действующим законодательством. Автором обозначаются некоторые проблемы в информационном освещении деятельности органов местного самоуправления, указывается на отсутствие правового регулирования электронных муниципалитетов на местном уровне. В ходе анализа федерального и муниципального законодательства предложены конкретные законодательные формулировки и организационные мероприятия, направленные на повышение степени гласности и укрепление легитимности органов местного самоуправления. общефрилософский метод, общенаучные методы познания (диалектический, системный, анализа и синтеза, индукции и дедукции), частнонаучные методы (сравнительно-правовой, формально-юридический, теоретико-прогностический) Научная новизна статьи заключается в обосновании взаимосвязи гласности и деятельности гражданского общества на муниципальном уровне, подтверждении влияния некоммерческого сектора на уровень прозрачности муниципальных органов. В качестве выводов предлагаются изменения в Федеральный закон "Об общих принципах организации местного самоуправления в Российской Федерации", Федеральный закон "Об основах общественного контроля в Российской Федерации", позволяющие усилить диалог муниципальных органов и гражданского общества.

Ключевые слова: гласность, местное самоуправление, гражданское общество, население, электронный муниципалитет, общественный контроль, доступ к информации, общественная палата, официальный сайт, муниципальный орган.

Abstract. The article considers the main legal mechanisms of ensuring publicity and transparency of local government, possessed by the civil society institutions according to the current legislation. The author outlines several problems of information coverage of local governments' activities; points at the lack of legal regulation of electronic municipalities on the local level. On the base of the analysis of federal and municipal legislation, the author proposes specific legislative and organizational measures, aimed at the improvement of publicity and legitimacy of local governments. The author applies general philosophical and general scientific methods of cognition (comparative-legal, formal-legal and theoretical and prognostic). The novelty of the study consists in the explanation of interconnection between publicity and the activity of the civil society on municipal level; in confirming the influence of the non-governmental sector on the level of transparency of municipal bodies. The author proposes the amendments to the Federal Law "On the general principles of local government organization in Russia", and the Federal Law "On the principles of public control in the Russian Federation", enhancing the dialogue between local governments and the civil society.

Key words: civil society, population, electronic municipality, public control, access to information, local government, the public chamber, publicity, official site, munucipal body.

$\mathrm{P}$ азвитие демократии в государстве и степень гласности государственных и муниципальных органов находятся в прямой взаимосвязи между собой: чем выше степень гласности, тем демократичнее становится государство. Гласность, открытость в деятельности - один из источников легитимности государственной власти и местного самоуправления, поскольку данный критерий отражает состояние политической, социально-экономической и духовной сферы жизни общества в государстве. В свою очередь, институты гражданского общества являются определенными меха-

Данная статья опубликована при поддержке Федерального государственного бюджетного учреждения "Российский гуманитарный научный фонд", проект № 15-53-00011 "Правовое регулирование деятельности институтов гражданского общества на муниципальном уровне" 
низмами повышения гласности деятельности государства и местного самоуправления. Государство не может полноценно функционировать без гражданского общества, как и гражданское общество не может существовать без государства.

К задачам правового регулирования взаимодействия государства и гражданского общества В.В. Гриб относит создание механизмов общественного контроля, пресечение коррупции, обеспечение механизмов гласности и открытости в деятельности власти, дальнейшую демократизацию функционирования государственной власти [4, с. 10].

Обеспечение «прозрачности», гласности деятельности органов местного самоуправления - важная составляющая эффективного функционирования институтов гражданского общества на муниципальном уровне, а также осуществления населением местного самоуправления. Как отмечает Д.С. Михеев, гласность предполагает открытость и публичность деятельности органов местного самоуправления, широкую информированность населения об этой деятельности, отчеты муниципальных органов власти перед населением, возможность общественного контроля со стороны населения за функционированием органов местного самоуправления, выявление и учет мнения населения при принятии наиболее важных решений по вопросам местного значения, а также возможность граждан влиять на выработку решений властных органов на местном уровне [9, с. 35]. Им же отмечается, что «гласность выполняет стержневую роль при осуществлении населением своих правомочий по отзыву депутатов, иных выборных лиц местного самоуправления» $[10$, с. 45]. Вызывает интерес закрепление механизмов обеспечения доступа населения к информации о деятельности органов местного самоуправления в муниципальных правовых актах.

Так, к примеру, решением Собрания депутатов муниципального образования «Волжский муниципальный район» Республики Марий Эл утверждено Положение об обеспечении доступа к информации о деятельности органов местного самоуправления муниципального образования «Волжский муниципальный район» [15], в соответствии с которым каждый орган местного самоуправления обязан обеспечивать доступ к информации о своей деятельности. К такой информации относится информация (в том числе документированная), созданная в пределах своих полномочий органами местного самоуправления или организациями, подведомственными органам местного самоуправления, либо поступившая в указанные органы или организации. В соответствии с вышеуказанным положением, к информации о деятельности органов местного самоуправления относятся также законы и иные нормативные правовые акты, в том числе муниципальные правовые акты, устанавливающие структуру, полномочия, порядок формирования и деятельности указанных органов и организаций, иная информация, касающаяся их деятельности.

9 февраля 2009 года вступил в силу Федеральный закон «Об обеспечении доступа к информации о деятельности государственных органов и органов местного самоуправления» [20], установивший основы правового регулирования отношений, связанных с обеспечением доступа к информации о деятельности государственных органов и органов местного самоуправления. Одним из способов обеспечения доступа к информации о деятельности государственных органов и органов местного самоуправления является размещение государственными органами и органами местного самоуправления информации о своей деятельности в сети «Интернет». Перечни же информации о деятельности органов местного самоуправления утверждаются в порядке, определяемом органами местного самоуправления, то есть фактически органы местного самоуправления сами определяют объем информации, размещаемой на официальном сайте муниципального образования.

Информационная прозрачность органов местного самоуправления может быть обеспечена посредством интернет-технологий. Как отмечают И.А. Мухачев и Б.Б. Адамоков, первоочередной задачей органов местного самоуправления должно стать обеспечение условий, при которых каждый человек будет иметь реальную возможность влиять на процесс выработки и принятия решений органами и должностными лицами местного самоуправления [12]. Следует согласиться с мнением Т.Н. Михеевой, указывающей, что электронная демократия уравновешивает возможности всех граждан - пользователей сети Интернет независимо от места жительства, социальной и профессиональной принадлежности и других критериев, оставляя поле для самореализации наиболее активным и инициативным [11]. Термин «электронный муниципалитет» еще не нашел широкого распространения в государственных органах и органах местного самоуправления, однако детальное его изучение поможет более глубоко понять механизмы непосредственной демократии на местном уровне.

Смысловое содержание словосочетания «электронный муниципалитет» не получило широкого распространения, так как начало складываться совсем недавно. Учитывая темпы информатизации и проникновения интернет-технологий в сферу государственного и муниципального регулирования, электронный муниципалитет - это будущее состояние муниципальной деятельности, а также качественно новый этап в развитии муниципаль- 


\section{Административное и муниципальное право 2 (98) • 2016}

ных образований, обеспечивающий гласность в деятельности органов местного самоуправления. По нашему мнению, термин «электронный муниципалитет» должен подразумевать создание социально ориентированных проектов на базе информационно-коммуникационных технологий на территории муниципалитета с целью достижения открытого диалога местных властей с населением, местными сообществами, а также с целью оказания населению различного рода услуг.

Электронный муниципалитет - это не только официальный сайт муниципального образования, под ним необходимо понимать механизм информационного взаимодействия органов местного самоуправления с населением, институтами гражданского общества, различными организациями по решению вопросов местного значения. Так, О.Н. Ванеев под электронным муниципалитетом понимает информационное взаимодействие органов местного самоуправления с населением и организациями с использованием информационно-коммуникационных технологий, основанное на принципах открытости, доступности и достоверности информации о деятельности органов местного самоуправления, свободы поиска, получения, передачи и распространения информации о деятельности органов местного самоуправления законным способом, соблюдения прав граждан на неприкосновенность частной жизни, личную и семейную тайну, защиту их чести и деловой репутации, прав организаций на защиту их деловой репутации при предоставлении информации о деятельности органов местного самоуправления [2, с. 62]. Кроме того, следует согласиться с Д. Сивоволовым, который указывает, что «участвуя в создании «электронного государства», местное самоуправление создает «электронное местное сообщество». И для создания более эффективного местного сообщества на основе современных средств телекоммуникации у муниципальной власти сегодня есть объективные возможности» [17, с. 67].

28 января 2002 года было принято постановление Правительства № 65 «0 федеральной целевой программе «Электронная Россия (2002 - 2010 годы)» [14], которое положило начало формированию электронного пространства для деятельности органов государственной власти и местного самоуправления в Российской Федерации. Одной из целей вышеуказанной программы является повышение качества взаимоотношений государства и общества путем расширения возможности доступа граждан к информации о деятельности органов государственной власти, повышения оперативности предоставления государственных и муниципальных услуг, внедрения единых стандартов обслуживания населения. Принятие данного нормативного акта и стало отправной точкой для введения таких сравнительно новых понятий, как электронное правительство, электронный муниципалитет, электронная услуга, цифровая подпись и т.д. В финансировании данной федеральной целевой программы планировалось и участие местных бюджетов, однако подобное реальное участие муниципальных бюджетов можно назвать пока экспериментами.

Следует особо отметить, что на сегодняшний день использование Интернета в интересах органов государственной власти и местного самоуправления проявляет собой яркий образ информационного неравенства. Причем различия в использовании интернет-технологий могут быть выражены не только в проблемах доступности Интернета в разных регионах России, но и в финансовых возможностях муниципалитетов. Для большинства муниципалитетов России не только на уровне городских и сельских поселений, но и муниципальных районов создание и поддержка сайта, хотя бы только для обозначения своего существования в Интернете, весьма проблематичны в силу жесточайшего дефицита бюджетных средств и отсутствия специалистов по созданию и сопровождению сайтов. Как отмечается в ежегодном докладе Общественной палаты России, дотационность муниципальных образований делает глав зависимыми от вышестоящих уровней власти, чем от населения собственного муниципалитета [5, с. 54]. В то же время некоторая часть органов государственной власти субъектов Российской Федерации чуть ли не ежегодно модернизирует до неузнаваемости свои сайты и порталы, демонстрируя все более современные и дорогие решения. Кроме того, как отмечает 0.С. Соколова, «федеральное законодательство в информационной сфере никоим образом не соотнесено с Законом о местном самоуправлении. Регулирование в данном Законе вопросов деятельности органов местного самоуправления в сфере информатизации не отражает задач, стоящих перед муниципальными образованиями в сфере, не стимулирует муниципалитеты к системной деятельности по формированию основ «электронного муниципального управления» [18]. Следует согласиться с Е.А. Незнамовой, отмечающей необходимость размещения на официальном Интернет-сайте муниципального образования информации об органах местного самоуправления, возможностях населения по участию в управлении, организацию работы населения с депутатами и представителями органов местного самоуправления в режиме «вопрос- ответ» [13].

Подводя итог вышесказанному, необходимо отметить, что приоритетным направлением в деятельности электронных муниципалитетов должна наряду с качественным и оперативным предостав- 
лением муниципальных услуг быть информационная связь местных властей с населением, то есть оперативное информирование населения о деятельности муниципалитета. Ведь подобная обратная связь даст возможность местному населению не только почувствовать влияние на их жизнь, но и предоставит возможность самим людям участвовать не только в реализации местных задач, но и в формировании муниципальной политики. Кроме того, на федеральном уровне необходимо установить конкретные требования к официальным сайтам муниципальных образований, а именно к объему информации, находящейся на сайте, возможности отправления обращений граждан в электронном виде муниципальным органам. Для успешного внедрения интернет-технологий в деятельность органов местного самоуправления всем муниципальным образованиям Российской Федерации необходимо осуществлять трансляцию заседаний представительных органов местного самоуправления и проводимых публичных слушаний в сети Интернет.

В этих целях необходимо дополнить ч. 1 ст. 15 Федерального закона от 06.10.2003 № 131-Ф3 «Об общих принципах организации местного самоуправления», закрепляющую вопросы местного значения муниципального района, пунктом 38 «информационное освещение деятельности местной администрации в сети «Интернет», аналогичные изменения целесообразно внести в часть 1 статьи 14 «вопросы местного значения поселения», дополнив пунктом 41; в часть 1 статьи 16 «вопросы местного значения городского округа», дополнив пунктом 45. Также для повышения «прозрачности» в деятельности представительного органа муниципального образования в статью 35 «представительный орган муниципального образования» Федерального закона от 06.10.2003 № 131-Ф3 «Об общих принципах организации местного самоуправления в Российской Федерации» необходимо ввести часть 11.2, изложив ее в следующей редакции: «11.2. Представительный орган муниципального образования обязан публиковать ежегодный отчет о проделанной работе в сети «Интернет».

Важнейшими институтами гражданского общества, обеспечивающими гласность деятельности всех уровней власти, являются общественные палаты. По мнению В.В. Гриба, именно Общественная палата России и общественные палаты субъектов Российской Федерации должны выступать в роли лидеров гражданского общества, играть роль «его представительного, контрольного и экспертного института» в государстве [3, с. 58]. А.В. Иванов определяет общественную палату субъекта Российской Федерации как постоянно действующий совещательный консультативный независимый орган пу- бличного права, обеспечивающий взаимодействие граждан и их объединений с органами государственной власти субъекта Российской Федерации и органами местного самоуправления, осуществляющего общественно-контрольную функцию в сферах правотворчества и правоприменения в целях защиты конституционных прав граждан, согласования и учета общественных интересов при формировании и реализации государственной политики [7, с. 9].

Так, деятельность Общественной палаты Республики Марий Эл регламентируется отдельным актом - Законом Республики Марий Эл от 29 апреля 2008 г. № 26-3 «Об Общественной палате Республики Марий Эл» [6]. В качестве цели создания Общественной палаты в законе указывается согласование общественно значимых интересов граждан и общественных объединений, обеспечение открытого, гласного обсуждения важнейших проблем государственного, экономического и социального развития Республики Марий Эл, совершенствование механизма контроля и учета общественного мнения при принятии решений органами государственной власти Республики Марий Эл и органами местного самоуправления, содействие процессу формирования институтов гражданского общества. Вышеуказанным законом подробно регламентируется состав и порядок формирования, статус членов, организация деятельности и структура Общественной палаты.

На местном уровне общественные палаты функционируют не повсеместно: это зависит, в первую очередь, от инициативности населения и общественных объединений, а также от финансовых возможностей муниципального образования. Так, решением Совета депутатов городского округа Подольск утверждено положение об Общественной палате муниципального образования «Городской округ Подольск Московской области» [16], в соответствии с которым Общественная палата муниципального образования выступает в качестве независимого коллегиального органа, осуществляющего свою деятельность на общественных началах. В качестве целей функционирования Общественной палаты указываются обеспечение взаимодействия граждан, проживающих на территории муниципального образования с органами местного самоуправления; учет общественно значимых законных интересов граждан, защиты их прав и свобод при формировании и реализации муниципальной политики по наиболее важным вопросам экономического и социального развития муниципального образования, а также защита законных прав общественных объединений, иных некоммерческих организаций граждан. Вышеуказанным муниципальным правовым актом подробно регулируются вопросы формирования Общественной палаты, статус ее члена, организация деятельности палаты. 


\section{Административное и муниципальное право 2 (98) 2016}

В силу негосударственной природы и содержания общественного контроля, его осуществление общественными палатами во многом повышает гласность и открытость местных органов.

2 августа 2014 года вступил в силу Федеральный закон от 21.07.2014 № 212-Ф3 «Об основах общественного контроля в Российской Федерации» [21], установивший правовые основы организации и осуществления общественного контроля за деятельностью органов государственной власти, органов местного самоуправления, государственных и муниципальных организаций, иных органов и организаций, осуществляющих в соответствии с федеральными законами отдельные публичные полномочия. Следует согласиться с мнением Р.Э. Арутюнян, указывающей, что «общественный контроль в современной России является воплощением важнейшей формы конструктивной социальной активности, которая находит свое выражение через специальный публично-властный механизм, характеризующийся самоорганизацией населения (особой формой деятельности гражданского общества) и государственной политикой по реализации контрольной функции управления, на основе сочетания интересов общества и государства» $[1$, с. 5].

В статье 3 вышеуказанного закона закрепляется право граждан Российской Федерации участвовать в осуществлении общественного контроля как лично, так и в составе общественных объединений и иных негосударственных некоммерческих организаций, при этом гражданин приобретает специальный статус, имеющий собственный перечень прав и обязанностей, - общественного инспектора или общественного эксперта. Часть 1 статьи 4 закона дает определение общественного контроля, под которым понимается деятельность субъектов общественного контроля, осуществляемая в целях наблюдения за деятельностью органов государственной власти, органов местного самоуправления, государственных и муниципальных организаций, иных органов и организаций, осуществляющих в соответствии с федеральными законами отдельные публичные полномочия, а также в целях общественной проверки, анализа и общественной оценки издаваемых ими актов и принимаемых решений. Законом предусматривается возможность создания специальных сайтов субъектами общественного контроля в целях информационного обеспечения деятельности (ст. 8).

Субъектами общественного контроля, согласно федеральному закону, являются 3 вида общественных палат: Общественная палата Российской Федерации, общественные палаты субъектов Российской Федерации, общественные палаты (советы) муниципальных образований, общественные советы при федеральных органах исполнительной власти, общественные советы при законодательных (представительных) и исполнительных органах государственной власти субъектов Российской Федерации. Также в ч. 2 ст. 9 указывается, что для осуществления общественного контроля могут создаваться общественные наблюдательные комиссии, общественные инспекции, группы общественного контроля, иные организационные структуры общественного контроля.

Интересно то, что в Федеральном законе «Об основах общественного контроля в Российской Федерации» предусматривается право субъектов общественного контроля на создание ассоциаций и союзов в целях координации своей деятельности, объединения усилий и средств для повышения эффективности общественного контроля (ст. 17).

Вместе с тем, считаем, что вышеуказанный Федеральный закон нуждается в дополнении главой, определяющей статус общественного контролера, его права, обязанности и ответственность. Также в целях наделения институтов гражданского общества инициативой разработки муниципальных правовых актов, часть 1 статьи 46 Федерального закона от 06.10.2003 № 131-Ф3 «подготовка муниципальных правовых актов» целесообразно изложить в следующей редакции: «Проекты муниципальных правовых актов могут вноситься депутатами представительного органа муниципального образования, главой муниципального образования, иными выборными органами местного самоуправления, главой местной администрации, органами территориального общественного самоуправления, инициативными группами граждан, общественной палатой (советом) муниципального образования, общественными наблюдательными комиссиями, общественными инспекциями, группами общественного контроля и иными организационными структурами общественного контроля муниципального образования, а также иными субъектами правотворческой инициативы, установленными уставом муниципального образования».

Что касается местного уровня, то здесь система общественного контроля должна охватывать деятельность представительного органа, исполнительно-распорядительного органа муниципального образования, деятельность муниципальных предприятий, учреждений, а также деятельность организаций жилищно-коммунального комплекса.

Механизм общественного контроля на местном уровне должен включать в себя, в первую очередь, прозрачность деятельности вышеуказанных органов, во-вторых, включенность населения в деятельность данных организаций, и, в-третьих, реальную возможность обжаловать действия и решения данных органов и учреждений. 
Рассуждая о реализации принципа гласности в местном самоуправлении Д.С. Михеев задается следующим вопросом: «А почему бы не расширить субъектный состав, включив в него местные общественные объединения?», указывая при этом следующее: «Ведь, по большому счету, члены этих объединений являются представителями населения муниципального образования, местного сообщества. Они аккумулируют в своих рядах наиболее активных граждан, не остающихся равнодушными к решению вопросов местного значения, в том числе заинтересованных в принятии недостающих, по их мнению, муниципальных правовых актов» [8, с. 18]. Следует согласиться с вышеуказанной точкой зрения, поскольку выразителями интересов местного населения являются все институты гражданского общества, функционирующие на муниципальном уровне.

По-нашему мнению, к мероприятиям муниципального контроля необходимо привлекать население и институты гражданского общества, что в значительной мере повысит легитимность контрольных мероприятий со стороны органов местного самоуправления. В этих целях предлагаем дополнить часть 1 ст. 17.1 Федерального закона «Об общих принципах организации местного самоуправления в Российской Федерации» «муниципальный контроль» следующим положением: «В необходимых случаях органами местного самоуправления к участию в мероприятиях муниципального контроля привлекаются население муниципального образования и/или общественная палата (совет) муниципального образования, общественные инспекции, группы общественного контроля или иные организационные структуры общественного контроля муниципального образования».

Подводя итог вышесказанному, необходимо отметить, что развитие интернет-технологий и общественного контроля на местном уровне является стимулирующими факторами для повышения уровня гласности и дальнейшего развития гражданского общества на местах. Приведенные выше рекомендации и законодательные предложения помогут более эффективно выстроить диалог «местное самоуправление - гражданское общество», улучшат существующие механизмы влияния местного населения на муниципальную политику, а также повысят степень гласности и легитимности органов местного самоуправления.

\section{Библиография:}

1. Арутюнян, Р.Э. Конституционно-правовой статус институтов общественного контроля при органах государственной власти субъектов Российской Федерации: автореф. дис. ... канд. юрид. наук: 12.00.02 / Арутюнян Радмила Эдуардовна.-М., 2011.-22 с.

2. Ванеев, О.Н. Электронный муниципалитет: пути информационного взаимодействия органов местного самоуправления с населением / О.Н. Ванеев // Современное право.-2010.-№ 4.-С. 59-62.

3. Гриб, В.В. Общественные советы (палаты) как ключевой институт взаимодействия органов государственной власти и институтов гражданского общества / В.В. Гриб // Юрист.-2010.-№ 12.-С. 57-59.

4. Гриб, В.В. Правовые вопросы институционализации взаимодействия гражданского общества и органов государственной власти / В.В. Гриб // Российская юстиция.-2011.-№ 3.-С. 10-11.

5. Доклад о состоянии гражданского общества в Российской Федерации за 2013 год.-М.: Общественная палата Российской Федерации, 2013.-183 с.

6. Законом Республики Марий Эл от 29 апреля 2008 г. № 26-3 «Об Общественной палате Республики Марий Эл» // Собрание законодательства Республики Марий Эл.-2008.-№ 5 (I).-Ст. 240.

7. Иванов, А.В. Конституционно-правовые основы формирования и деятельности Общественных палат субъектов Российской Федерации (на опыте Центрального федерального округа): автореф. дис. ... канд. юрид. наук: 12.00.02 / Иванов Андрей Валерьевич.-М., 2011.-24 с.

8. Михеев, Д.С. Взаимодействие граждан с муниципальными органами как механизм осуществления принципа гласности местного самоуправления / Д.С. Михеев // Российская юстиция.-2012.-№ 7.-С. 17 - 19.

9. Михеев, Д.С. Об отдельных аспектах в правовом регулировании принципа гласности местного самоуправления / Д.С. Михеев // Закон и право.-2009.-№ 3.-С. 35-37.

10. Михеев, Д.С. Ответственность органов местного самоуправления перед населением как элемент принципа гласности / Д.С. Михеев // Закон и право.-2014.-№ 4.-С. 43-45.

11. Михеева, Т.Н. Об актуальных тенденциях в правовом регулировании статуса Общественной палаты Российской Федерации / Т.Н. Михеева // Юридический мир.-2013.-№ 5.-С. 11-13.

12. Мухачев, И.В. Онлайн обсуждение проекта устава муниципального образования, его изменений и дополнений / И.В. Мухачев, Б.Б. Адамоков // Общество и право.-2012.-№ 4(41).-С. 73-76.

13. Незнамова, Е.А. Местное самоуправление: прошлое, настоящее, будущее: монография / Е.А. Незнамова.-М.: РАГС, 2009.-268 c.

14. Постановление Правительства РФ от 28.01.2002 № 65 «0 федеральной целевой программе «Электронная Россия (2002-2010 годы)» // СЗ РФ.-04.02.2002.-№ 5.-Ст. 531.

15. Решение Собрания депутатов муниципального образования «Волжский муниципальный район» Республики Марий Эл от 18.04.2012. № 31-8 «Об утверждении положения об обеспечении доступа к информации о деятельности органов местного самоуправления муниципального образования «Волжский муниципальный район» // Волжские вести.-17.05.2012.-№ 20. 


\section{Административное и муниципальное право 2 (98) • 2016}

16. Решение Совета депутатов городского округа Подольск Московской области от 20.09.2011 № 11/16 «Об утверждении Положения об Общественной палате муниципального образования «Городской округ Подольск Московской области» (ред. 29.08.2013)// Подольский рабочий.-26.10.2011.-№ 82.

17. Сивоволов, Д. Роль муниципальной власти в создании «электронного государства» в России / Д. Сивоволов // Муниципальная власть.-2010.-№ 6.-С. 66-67.

18. Соколова, О.С. Административно-правовое регулирование муниципальных информационных отношений / 0.С. Соколова // Административное и муниципальное право-2010.-№ 9.-С. 85-91.

19. Федеральный закон от 09.02.2009 № 8-ФЗ «Об обеспечении доступа к информации о деятельности государственных органов и органов местного самоуправления» [официальный текст принят Гос. Думой 21 января 2009 года: по состоянию на 1 января 2014 года] // СЗ РФ.-2009.-№ 7.-Ст. 776.

20. Федеральный закон от 09.02.2009 № 8-Ф3 «Об обеспечении доступа к информации о деятельности государственных органов и органов местного самоуправления» [официальный текст принят Гос. Думой 21 января 2009 года: по состоянию на 1 декабря 2014 года] // СЗ РФ.-2009.-№ 7.-Ст. 776.

21. Федеральный закон от 21.07.2014 № 212-Ф3 «Об основах общественного контроля в Российской Федерации» [официальный текст принят Гос. Думой 04 июля 2014 года] // СЗ РФ.-2014.-№ 30.-Ст. 4213

\section{References (transliterated):}

1. Arutyunyan, R.E. Konstitutsionno-pravovoi status institutov obshchestvennogo kontrolya pri organakh gosudarstvennoi vlasti sub"ektov Rossiiskoi Federatsii: avtoref. dis. ... kand. yurid. nauk: 12.00.02 / Arutyunyan Radmila Eduardovna.-M., 2011.-22 s.

2. Vaneev, O.N. Elektronnyi munitsipalitet: puti informatsionnogo vzaimodeistviya organov mestnogo samoupravleniya s naseleniem / O.N. Vaneev // Sovremennoe pravo.-2010.-№ 4.-S. 59-62.

3. Grib, V.V. Obshchestvennye sovety (palaty) kak klyuchevoi institut vzaimodeistviya organov gosudarstvennoi vlasti i institutov grazhdanskogo obshchestva / V.V. Grib // Yurist.-2010.-№ 12.-S. 57-59.

4. Grib, V.V. Pravovye voprosy institutsionalizatsii vzaimodeistviya grazhdanskogo obshchestva i organov gosudarstvennoi vlasti / V.V. Grib // Rossiiskaya yustitsiya.-2011.-№ 3.-S. 10-11.

5. Doklad o sostoyanii grazhdanskogo obshchestva v Rossiiskoi Federatsii za 2013 god.-M.: Obshchestvennaya palata Rossiiskoi Federatsii, 2013.-183 s.

6. Zakonom Respubliki Marii El ot 29 aprelya 2008 g. № 26-Z «Ob Obshchestvennoi palate Respubliki Marii El» // Sobranie zakonodatel'stva Respubliki Marii El.-2008.-№ 5 (I).-St. 240.

7. Ivanov, A.V. Konstitutsionno-pravovye osnovy formirovaniya i deyatel'nosti Obshchestvennykh palat sub"ektov Rossiiskoi Federatsii (na opyte Tsentral'nogo federal'nogo okruga): avtoref. dis. ... kand. yurid. nauk: 12.00.02 / Ivanov Andrei Valer'evich.-M., 2011.-24 s.

8. Mikheev, D.S. Vzaimodeistvie grazhdan s munitsipal'nymi organami kak mekhanizm osushchestvleniya printsipa glasnosti mestnogo samoupravleniya / D.S. Mikheev // Rossiiskaya yustitsiya.-2012.-№ 7.-S. 17 - 19.

9. Mikheev, D.S. Ob otdel'nykh aspektakh v pravovom regulirovanii printsipa glasnosti mestnogo samoupravleniya / D.S. Mikheev // Zakon i pravo.-2009.-№ 3.-S. 35-37.

10. Mikheev, D.S. Otvetstvennost' organov mestnogo samoupravleniya pered naseleniem kak element printsipa glasnosti / D.S. Mikheev // Zakon i pravo.-2014.-№ 4.-S. 43-45.

11. Mikheeva, T.N. Ob aktual'nykh tendentsiyakh v pravovom regulirovanii statusa Obshchestvennoi palaty Rossiiskoi Federatsii / T.N. Mikheeva // Yuridicheskii mir.-2013.-№ 5.-S. 11-13.

12. Mukhachev, I.V. Onlain obsuzhdenie proekta ustava munitsipal'nogo obrazovaniya, ego izmenenii i dopolnenii / I.V. Mukhachev, B.B. Adamokov // Obshchestvo i pravo.-2012.-№ 4(41).-S. 73-76.

13. Neznamova, E.A. Mestnoe samoupravlenie: proshloe, nastoyashchee, budushchee: monografiya / E.A. Neznamova.-M.: RAGS, 2009.-268 s.

14. Postanovlenie Pravitel'stva RF ot 28.01.2002 № 65 «O federal'noi tselevoi programme «Elektronnaya Rossiya (20022010 gody)» // SZ RF.-04.02.2002.-№ 5.-St. 531.

15. Reshenie Sobraniya deputatov munitsipal'nogo obrazovaniya «Volzhskii munitsipal'nyi raion» Respubliki Marii El ot 18.04.2012. № 31-8 «Ob utverzhdenii polozheniya ob obespechenii dostupa kinformatsii o deyatel'nosti organov mestnogo samoupravleniya munitsipal'nogo obrazovaniya «Volzhskii munitsipal'nyi raion» // Volzhskie vesti.-17.05.2012.-№ 20.

16. Reshenie Soveta deputatov gorodskogo okruga Podol'sk Moskovskoi oblasti ot 20.09.2011 № 11/16 «Ob utverzhdenii Polozheniya ob Obshchestvennoi palate munitsipal'nogo obrazovaniya «Gorodskoi okrug Podol'sk Moskovskoi oblasti» (red. 29.08.2013)// Podol'skii rabochii.-26.10.2011.-№ 82.

17. Sivovolov, D. Rol' munitsipal'noi vlasti v sozdanii «elektronnogo gosudarstva» v Rossii / D. Sivovolov // Munitsipal'naya vlast'.-2010.-№ 6.-S. 66-67.

18. Sokolova, O.S. Administrativno-pravovoe regulirovanie munitsipal'nykh informatsionnykh otnoshenii / O.S. Sokolova // Administrativnoe i munitsipal'noe pravo.-2010.-№ 9.-S. 85-91.

19. Federal'nyi zakon ot 09.02.2009 № 8-FZ «Ob obespechenii dostupa k informatsii o deyatel'nosti gosudarstvennykh organov i organov mestnogo samoupravleniya» [ofitsial'nyi tekst prinyat Gos. Dumoi 21 yanvarya 2009 goda: po sostoyaniyu na 1 yanvarya 2014 goda] // SZ RF.-2009.-№ 7.-St. 776.

20. Federal'nyi zakon ot 09.02.2009 № 8-FZ «Ob obespechenii dostupa k informatsii o deyatel'nosti gosudarstvennykh organov i organov mestnogo samoupravleniya» [ofitsial'nyi tekst prinyat Gos. Dumoi 21 yanvarya 2009 goda: po sostoyaniyu na 1 dekabrya 2014 goda] // SZ RF.-2009.-№ 7.-St. 776.

21. Federal'nyi zakon ot 21.07.2014 № 212-FZ «Ob osnovakh obshchestvennogo kontrolya v Rossiiskoi Federatsii» [ofitsial'nyi tekst prinyat Gos. Dumoi 04 iyulya 2014 goda] // SZ RF.-2014.-№ 30.-St. 4213 